\title{
The Effectiveness of Positive Communication Skills in Reducing Pain during Physiotherapy Session: A Quantitative Result from Questionnaire Surveys of Palestinian Orthopaedic Patients
}

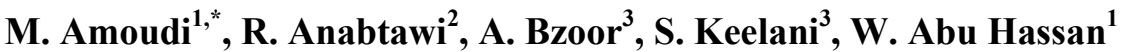 \\ ${ }^{1}$ Health Sciences Department, Arab American University, Palestine \\ ${ }^{2}$ Nursing Department, Arab American University, Palestine \\ ${ }^{3}$ Physiotherapy Department, Arab American University, Palestine
}

Copyright $\bigcirc 2017$ by authors, all rights reserved. Authors agree that this article remains permanently open access under the terms of the Creative Commons Attribution License 4.0 International License

\begin{abstract}
Background: Physiotherapist has to communicate on a daily basis with clients and their families ,friends , and other health care professionals. Physiotherapists assist patients with their pain in primary care settings aiming at relieving their pain, and improving their quality of life. Studies showed that poor communication often results in many negative consequences. However, few studies provide sufficient evidence to support the use of positive communication

0.732. Conclusion: Physiotherapist communication skills play an essential role during treatment sessions to relive patient's pain. Our data showed high impact of positive communication skills in reducing pain among orthopedic patient during physiotherapy session. The results show positive impact on patient's psychology and physiologies which are inseparable. However, results showed there are no statistical variances between study samples according to the independent variables.
\end{abstract} skills in reducing pain among orthopedic patient. Objectives: Examine the effectiveness of positive communication skills in reducing pain among orthopedic patient during physiotherapy sessions in 20 Palestinian rehabilitation centers dispensers on several areas and through an investigative program for the views of the orthopaedic patients among interview questionnaire for the inclusion of positive communication skills in the treatment session and its impact on relieving their pain. Methods: The current study employed non-experimental design by conducting a self-report questionnaires has approved by 3 of academic in the physiotherapy section at AAUJ, the study group covered a total number of (96) orthopaedic patients used a normal distribution to calculate an optimum sample size randomly selected from 20 centers in different Palestinian regions; 48 were male and 48 were female. Results: There was statistically significant change in intensity of pain in correlation with integration positive communication skill among orthopedic patients regardless of nature of disease during physiotherapy sessions indicate that (sig. $=0.00, p<0.05$ ). Non-significant correlations were evident between patient's demographic factors, pain and disease related factors, and change in the intensity of pain. Validity and reliability of the instrument were tested and the total instrument reliability test (Cronbach's Alpha) was
Keywords Communication Skills, Pain, Physiotherapy Session, Orthopaedic Patient

\section{Introduction}

Orthopedic and physiotherapy are integrated in practice performance for relieving pain, decreasing the effect of injury and deformity among patients.

The physiotherapist is required to communicate on a daily basis with clients, clients' families and friends, third-party payers, equipment vendors, and other health care professionals. They work as members of a health care team. The ethos of a physiotherapist defines what good occupational practices should characterize a physiotherapist. General principles cover an evaluation of an adequate attitude, i.e. respectable coexistence and behaviour with respect to others, as well as normal social relationships and a positive attitude towards oneself and the surrounding world [1].

Communication involves sending and receiving information, emotions, messages and thoughts through visual, auditory and kinesthetic channels that indicated by 
Barringer B et al. [2]. When we communicate effectively, we can be more efficient and provide optimal care to our clients .Initially, before we can effectively treat a client ,physiotherapist (PTS) should gain an understanding of patient perception on his/her illness . Patient concerns can be wide ranging including (fear of death, mutilation , disability, ominous attribution to pain symptoms, fear of leaving home, denial of reality of medical problem ) also physiotherapist should understanding the psychology of patient is step toward ensuring effective patient physiotherapist relationship as Adler R et al. [3] proposed. Health care professionals agree that health care providers must possess effective communication skills to motivate clients, promote compliance with treatment protocols, and ensure appropriate and cost-efficient outcomes. A study by Henkin et al. [4] ensured the need for formal communication training that is professionally relevant, efficient, and designed to strengthen desired communication competencies .They are required to make autonomous clinical and ethical decisions based on communication and relationships with their patients, other health care team members, and health care institutions according to Delany $\mathrm{C}, \mathrm{m}$ et al. [5].The subjective opinion of a patient is the ultimate measure of physiotherapists professional attitude. Even the most able team of therapists will not be able to create a collaborative framework unless their patients are willing to grasp the opportunity offered to them, Thomson D [6]. In this occupation, there is also a need for sensitivity to others, tolerance, acceptance, understanding of the psychological essence of suffering and illness, and above all, motivation to provide assistance for patients. According to the self-determination theory, support from health care practitioners can promote patient's autonomous motivation and greater long-term behavioural Persistence, Lonsdale C et al. [7].

Studies show that poor communication often results in many negative consequences, so it's the most aspect you should be skilled in to get to make a good first impression. Communication occur at four level, the most important one is interpersonal level, between the patient and you as a part of rehabilitation team. The practitioner should consider the two methods of communication: verbally and/or non-verbally. Verbal messages are influenced by paralanguage cues, such as tone of voice, pitch, volume and speed. Nonverbal messages may be sent intentionally or unintentionally, that include facial expression, touch, proxemics and behavior, including the importance of humor and supportive words every now and then as Newton BJ et al. [8] mentioned .Pain for patients is a multifactorial experience influenced among other things, by culture, previous pain experience, belief, mood and ability to cope with as Merskey $\mathrm{N}$ et al. [9] prescribed. The biopsychosocial model of pain described by Flor $\mathrm{H}$ et al. [10] proposed that biological factors can influence physiological changes and that psychological factors are reflected in the appraisal and perception of internal physiological phenomena.
Upshur C. C. et al. [11] proposed that patient who were depressed and experienced communication difficulties may be more likely to catastrophize their pain and tend to report or experience pain and that to conflict between client and physician, loss of confidence, lack of patient communication and adherence, lack of patient satisfaction and all that affect negatively on the quality of life. Magni G [12] reported that patients who suffered from depression are more likely to score their pain as more severe than patients without depression, even if there is no obvious medical basis for the difference in pain intensity.

Evidently limited previous studies (identically related to the study state object topic), which make it worth and essential. This investigation was based on the psychophysiological frame of references, which is according to Dultamel K[13]deals with improve pain management related to increasing communication skills in the cancer patient.

Psychophysiology has revealed that emotion and cognition are interdependent .Strong emotions can alter thought process, perceptions ,beliefs ,attitudes and expectancies .Conversely, thoughts can generate negative or positive emotional status, and the physiological changes associated with such states can interact with tissue injury or inflammation and alter both the sensory and affective aspects of pain, James $P$ et al. [14].The Corner stone in this study to take a human illness in a view which the psychology and physiology inseparable, so we should concentrate at the beginning at the patient's psych disguised that control his responses and reflexes including pain reflex. If we through effective communication decrease patients stress, fears, depression, unconfidently, and loss of hope that naturally alter the normal physiology will amplifies reflexes including pain reflex which the most compliant and at the head of our treatment goal reducing it.

\section{Aim of the Study}

The current study was designed to investigate the effect of positive communication skills in reducing pain among orthopedic patients during physiotherapy sessions in Palestinian rehabilitation centers. The researchers hope the result will be positive to make the physiotherapist more awareness that communication skills are critical point among sessions should be conceder to motivate, increase patient confidence and enhance outcomes. Also, the research will place a good stage impractical implementations for physical therapists especially for students before they go to clinical field.

The following research problems were formulated:

1. What is the impact level of positive communication skills in reducing pain among orthopaedic patient during physiotherapy session?

2. Are there any differences in the level of professional communication competences according to the model of: 
A-age, gender, social status, educational and economic status, occupation and attitudes toward importance of positive communication skill in reducing pain

B-diagnosis, period of pain, number of session and range of pain intensity that alleviate through session full of positive communication skill

\section{Methodology}

\section{A. Research Design}

Study design is a Non _ experimental, which the most suitable, cause the nature of problems in the health science field usually prevents investigators from proving causal effect: that is ,they cannot often state definitively that the changes they see at the end of their studies are caused solely by the treatment intervention there is one group of subjects ,the investigator looking for a relationship between variables, the researcher tests a hypothesis ,comparing two variables by measuring differences and looking for a relationship, to investigate the effect of positive communication skills in reducing pain among orthopedic patients during physiotherapy sessions in Palestinian rehabilitation centers.

\section{B. Ethical Consideration}

Ethical approval was obtained from ethical committee for private and public rehabilitation centers prior data collection. all personal information obtained by the survey was kept confidential and participants' permission was taken by sign in a consent to assure their voluntary participation.

\section{Research Setting and Sampling}

The study sample consisted of (96) orthopedic patients ;48 males and 48 females, used a normal distribution to calculate an optimum sample size, confidence level $95 \%$ and margin of error (9),6 patients were selected from each center, which was a total of 18 centers randomly selected from governmental and private Palestinian rehabilitation centers in deferent regions. The patient sample comprised patients aged between 14 and 68 years, the highest percentage of them diagnosed with a fracture.

\section{Data Collection Process}

A Self-designed questionnaire was developed and interviewed by the authors based on insertion all terms related to positive communication skills in a way patient can decide if really effect and reducing pain or not and the patient mark the number of sessions and the percent of improvement had received. Data analysis was done by the researchers. Means have been computed for the continuous numeric variables. To illustrate the main characteristics of the respondents, frequency tables have been used. Advanced statistical analysis was conducted to explore potential relationships between variables, student t-test and one way ANOVA test to examine potential relationships between the continuous variables. $P$ value less than or equal
0.05 was considered statistically significant.

\section{E. Instrumentation}

The researchers designed the questionnaire to express the Patient's level of perception about effect of the included positive communication skills among physiotherapy session by rating five points Likert scale $(1=$ strongly disagree, $2=$ disagree, $3=$ uncertain, $4=$ agree, $5=$ strongly agree $)$. While Cronbachs' Alpha Coefficient test was used to measure the reliability of the instrument between each domain and the whole of the instrument. In this study the Cronbachs' Alpha value of the instrument was 0.732 , which are acceptable according to Nunnally and Bernstein's (1994) guidelines for exploratory research.

The questionnaire was build up and is organized in three parts:

- Part one: Include personal questions related to (age, Gender, address, social status, level of education, economic status, occupation).

- Part two: consist of questions that describe the characteristics of pain including diagnosis, nature, quality, duration, site of pain, and intensity of pain, and the number of sessions.

- Part three: Include Likert scale that was used to determine patients' perception when using communication skills among physiotherapy sessions in reducing pain intensity and increasing patient's cooperation during physiotherapy sessions.

Verbal messages are included in the questionnaires influenced by paralanguage cues, such as tone of voice, pitch, volume and speed. Nonverbal messages that include facial expression, touch, proxemics and behavior, include the importance of humor and supportive words every.

\section{F. Statistical Analysis}

The data obtained were subjected to statistical analysis by using the Statistical Package for Social Sciences (SPSS) software. The results showed that $50 \%$ of the study subjects agree that positive communication skills provide major help in relieving pain , 29.2\% indicated it has moderate help and $20.8 \%$ believed it has a little effect .The significance of quantitative variables was examined with the use of single-factor analysis of variance. The $p$ values $<0.05$ were considered statistically significant

\section{Results}

\subsection{Descriptive Statistics}

Table 1 describes the age distribution among participants was $34.7 \%(n=33)$ of patients were between $14-24$ years old, $43.2 \%(n=41)$ were between $25-35$ years old, $9.5 \%(n=9)$ of patients were aged between 36-46 years old, 9.5\% $(\mathrm{n}=9)$ were between $47-57$ years old, and $3.2 \%(n=3)$ were between 58-68 years old. 
Table 1. Description of the personal characteristics of the study participants $(\mathrm{N}=96)$

\begin{tabular}{|c|c|c|c|}
\hline & & Count & Percent $\%$ \\
\hline \multirow{2}{*}{ Gender } & Male & 48 & 50.0 \\
\hline & Female & 48 & 50.0 \\
\hline \multirow{5}{*}{ Age } & $14-24$ & 33 & 34.7 \\
\hline & $25-35$ & 41 & 43.2 \\
\hline & $36-46$ & 9 & 9.5 \\
\hline & $47-57$ & 9 & 9.5 \\
\hline & $58-68$ & 3 & 3.2 \\
\hline \multirow{2}{*}{ Social Status } & Single & 46 & 47.9 \\
\hline & Married & 50 & 52.1 \\
\hline \multirow{5}{*}{ Level of Education } & Diploma & 20 & 20.8 \\
\hline & BA & 39 & 40.6 \\
\hline & MSC & 5 & 5.2 \\
\hline & $\mathrm{PhD}$ & 1 & 1.0 \\
\hline & Uneducated & 31 & 32.3 \\
\hline \multirow{3}{*}{ Economic status } & High & 10 & 10.4 \\
\hline & Moderate & 65 & 67.7 \\
\hline & Low & 21 & 21.9 \\
\hline \multirow{6}{*}{ Occupation } & House keeper & 10 & 10.4 \\
\hline & Student & 18 & 18.8 \\
\hline & government sector & 19 & 19.8 \\
\hline & private sector & 31 & 32.3 \\
\hline & Unemployed & 9 & 9.4 \\
\hline & Other & 9 & 9.4 \\
\hline
\end{tabular}

For addition, 47.9\% ( $\mathrm{n}=46)$ were single, while $52.1 \%$ $(\mathrm{n}=50)$ of the participant were married. The data also showed that $32.3 \%(n=31)$ were uneducated, $20.8 \% \quad(n=20)$ of patients have diploma degree, $40.6 \% \quad(n=39)$ have baccalaureate degree, 5.2\% $(n=5)$ have MSC degree and 1\% $(\mathrm{n}=1)$ has $\mathrm{PhD}$.Regarding to economic status, the results showed $10.4 \%(n=10)$ in a high economic level, $67.7 \%$ $(n=65)$ in moderate economic level while $21.9 \%(n=21)$ in a low economic level. $10.4 \%(\mathrm{n}=10)$ of the participants were house keeper, 18.8\% ( $\mathrm{n}=18)$ were student, 19.8\% $(\mathrm{n}=19)$ work in a government sector, $32.3 \%(\mathrm{n}=31)$ work in private sector, $9.4 \%(n=9)$ were unemployed while $9.4 \%(n=9)$ work in other occupations.

Table 2 describes the diagnosis for all participants, and the results showed that $24.5 \%(\mathrm{n}=23)$ of participant had fracture, $17 \%(n=16)$ had tendon and ligament injury, $22.3 \%(n=21)$ had low back pain, 5.3\% $(n=5)$ had frozen shoulder, $2.1 \%$ $(n=2)$ had carpal tunnel syndrome (CTS), 5.3\% $(n=5)$ had osteoarthritis, 2.1\% $(\mathrm{n}=2)$ had rheumatoid arthritis, $2.1 \%$ $(n=2)$ had lateral epicondylitis. 9.6\% $(n=9)$ had disc protrusion and 9.6\% $(n=9)$ had other orthopaedic diseases. $65.4 \%(n=53)$ of the participants had a localized pain while $34.6 \%(n=28)$ their pain was extended to another part of their body. $62.1 \%(n=36)$ of the participant's pain was intermittent while $37.9 \%(n=22)$ the pain was continuous. Regarding the diurnal time of getting pain, 53.8\% $(n=35)$ got their pain during all the day, $24.6 \%(n=16)$ got their pain at the night, while $21.5 \%(n=14)$ of the participants got their pain in the morning. $73.5 \%(n=36)$ of the studied sample their pain were deep in its quality, and $26.5 \%(\mathrm{n}=13)$ had dull pain.

Regarding to the duration of pain; $19.8 \%(n=19)$ of the participants reported that their complain of pain lasts within less than 3 weeks, 29.2\% $(n=28)$ complaint of their pain from 3 weeks to two months, while $10.4 \%(n=10)$ the pain took from two months to three months, and $40.6 \%(n=39)$ of the participants' pain lasts more than three months.

The intensity of pain were divided to mild, moderate, and severe which is revealed by result as follow $7.3 \%(n=7)$, $55.2 \%(n=53)$ and $37.5 \%(n=36)$ respectively. 
Table 2. Descriptive statistic about characteristics of pain, location, type, time, quality, duration, and intensity of pain among study participant

\begin{tabular}{|c|c|c|c|}
\hline & & Count & Percent $\%$ \\
\hline \multirow{10}{*}{ Etiology of Pain } & Fractures & 23 & 24.5 \\
\hline & Tendon and ligament injury & 16 & 17.0 \\
\hline & Low back pain (LBP) & 21 & 22.3 \\
\hline & Frozen shoulder & 5 & 5.3 \\
\hline & Carpal tunnel syndrome (CTS) & 2 & 2.1 \\
\hline & Osteoarthritis & 5 & 5.3 \\
\hline & Rheumatoid arthritis & 2 & 2.1 \\
\hline & Lateral epicondylitis & 2 & 2.1 \\
\hline & Disc Protrusion & 9 & 9.6 \\
\hline & Other & 9 & 9.6 \\
\hline \multirow{2}{*}{ Location of Pain } & Localized & 53 & 65.4 \\
\hline & Extended & 28 & 34.6 \\
\hline \multirow{2}{*}{ Type of pain } & Intermittent & 36 & 62.1 \\
\hline & Continuous & 22 & 37.9 \\
\hline \multirow{3}{*}{ Time of pain } & At morning & 14 & 21.5 \\
\hline & All the day & 35 & 53.8 \\
\hline & At night & 16 & 24.6 \\
\hline \multirow{2}{*}{ Quality of pain } & Dull & 13 & 26.5 \\
\hline & Deep & 36 & 73.5 \\
\hline \multirow{4}{*}{ Duration of Pain } & Less than 3 weeks & 19 & 19.8 \\
\hline & From 3 weeks to two months & 28 & 29.2 \\
\hline & From two months to three months & 10 & 10.4 \\
\hline & More than three months & 39 & 40.6 \\
\hline \multirow{3}{*}{ Intensity of Pain } & Mild pain & 7 & 7.3 \\
\hline & Moderate pain & 53 & 55.2 \\
\hline & Severe pain & 36 & 37.5 \\
\hline
\end{tabular}

Table 3. Means and Standard deviations of degrees of communication acceptance by the patient toward physiotherapist during physiotherapy session:

\begin{tabular}{|c|c|c|c|}
\hline Communication skill & Mean & Standard Deviation & Degree of acceptance \\
\hline $\begin{array}{l}\text { If the physiotherapist concerns about what I am saying, and interested in details that I tell } \\
\text { during the session, meant he is care of gathering any information to got a clear picture of my } \\
\text { health. }\end{array}$ & 4.4 & \pm 0.9 & High \\
\hline $\begin{array}{l}\text { I feel good when the therapist said" I understand you", I feel with you" this reflect a good } \\
\text { feeling for me. }\end{array}$ & 4.4 & \pm 0.8 & High \\
\hline I think my psychological status affect my health situation. & 4.1 & \pm 1.1 & High \\
\hline $\begin{array}{l}\text { I feel better and motivated when physiotherapist encourages me during exercise session by } \\
\text { using phrases like "you can do it". }\end{array}$ & 4.1 & \pm 1.0 & High \\
\hline I feel comfort when my family or/and friends are beside me during the physiotherapy session. & 3.8 & \pm 1.2 & High \\
\hline I feel more self-aware when physiotherapist explains the treatment plan for me. & 4.3 & \pm 0.9 & High \\
\hline $\begin{array}{l}\text { If physiotherapist shows commitment to scheduled time of the session, I also show my } \\
\text { commitment. }\end{array}$ & 4.2 & \pm 1.0 & High \\
\hline I feel comfort when I talk about my problem with the physiotherapist. & 3.8 & \pm 1.1 & High \\
\hline When I feel depressed, I don't want to speak with my physiotherapist or doing the exercise. & 3.3 & \pm 1.1 & Moderate \\
\hline Using humor by physiotherapist during session improve my psychological aspect. & 4.1 & \pm 0.9 & High \\
\hline $\begin{array}{l}\text { If my therapist is listening to me attentively, this contributes the alleviation of my tension and } \\
\text { pressure. }\end{array}$ & 4.2 & \pm 0.9 & High \\
\hline I feel prayers and spiritual practices ease my pain feeling. & 4.2 & \pm 1.0 & High \\
\hline I think that the first impression about the physiotherapist is very important for me. & 4.3 & \pm 1.0 & High \\
\hline $\begin{array}{l}\text { Using different voice tone, speed of the speech, affect me positively during physiotherapy } \\
\text { session. }\end{array}$ & 3.7 & \pm 1.3 & High \\
\hline I feel talking with my therapist is wasting of time. & 2.1 & \pm 1.2 & Low \\
\hline I prefer to receive physiotherapy from different physiotherapist in each session. & 1.9 & \pm 1.3 & Low \\
\hline $\begin{array}{l}\text { If I have bad first impression of my physiotherapist, I can't change it even if he/she change the } \\
\text { way of dealing with me. }\end{array}$ & 3.1 & \pm 1.2 & Moderate \\
\hline
\end{tabular}


Table (3) shows the patient acceptance of communication skills recruited by physiotherapist among the session, in which the results showed positive impact and high acceptance toward positive communication practices the physiotherapist recruited. Higher mean scores were obtained for the following statement which describes the effectiveness of inclusion positive communication skills:

If the physiotherapist concerns about what I am saying, and interested in details that I tell during the session,meant he is care of gathering any information to get a clear picture of my health, with a mean $4.4 \pm 0.9$, means the majority of patients agree that the therapist who interested in details care about their health.

Empathy of physiotherapist towards patient showed also high mean $4.4 \pm 0.8$ as patients reported they feel good when the therapist said" I understand you", I feel with you".

In addition, the patients reveal that they feel more self-aware when physiotherapist explains the treatment plan for them, had high mean value $4.3 \pm 0.9$.

According to statements rated moderate include:

"When I feel depressed, I don't want to speak with my physiotherapist or doing the exercise". Have mean value $3.3 \pm 1.1$ which indicate the depression delay the improvement or make the patient's condition worse.

Mean value of the statement "If I have bad first impression of my physiotherapist, I can't change it even if he/she change the way of dealing with me" was $3.1 \pm 1.2$, clients' opinion were moderated regard change their first impression toward therapist. So, therapist should take in consideration when dealing with client the importance of facial expression and voice tone and all positive communication skills during the sessions.

As for the statement that rated low:

The results toward the statement "I feel talking with my therapist is wasting of time", was significantly low which reveal that client feel comfortable when communicate with therapist and this help to break down barriers or limitation which give chance to understand their needs and hopes.

Most patients didn't agree to change their physiotherapist who starts with them the physiotherapy session when they were asked if they prefer to receive physiotherapy from different physiotherapist in each session, and they feel better dealing with same therapist along the treatment sessions.

Table (4) manifest communication skills for therapist which indicate highest percent $(86 \%)$ of therapist practice talking and listening skills during physiotherapy sessions which allowed the client to feel respectful, $(67.7 \%)$ acquired skills related to psychological knowledge and strengthening it, (55.9\%) also agreed on the use dynamic effective skills and facial gestures and hand movements during physiotherapy sessions.

On the contrary, $66.7 \%$ of the participant answered that the therapist doesn't including families and friends among the session, $(60.2 \%)$ didn't notice that cognitive skills and intelligence of the physiotherapist it's used. And (51.6\%) reported the therapist didn't guarantee situational awareness including incorporating environment on exercises and selecting the right environment for the therapy session.
Table 4. Descriptive statistic for communication skills used by the therapist through the session

\begin{tabular}{|l|c|c|c|c|}
\hline \multirow{2}{*}{} & \multicolumn{2}{|c|}{ Yes } & \multicolumn{2}{c|}{ No } \\
\cline { 2 - 5 } & Count & $\begin{array}{c}\text { Percent } \\
\%\end{array}$ & Count & $\begin{array}{c}\text { Percent } \\
\%\end{array}$ \\
\hline Talking and listening skills. & 80 & 86.0 & 13 & 14.0 \\
\hline $\begin{array}{l}\text { Skills related to improvement of } \\
\text { psychological status and stress relief. }\end{array}$ & 63 & 67.7 & 30 & 32.3 \\
\hline $\begin{array}{l}\text { Social influence through including } \\
\text { patients' family and friends among } \\
\text { the session. }\end{array}$ & 31 & 33.3 & 62 & 66.7 \\
\hline $\begin{array}{l}\text { Dynamic effective skills, facial } \\
\text { gestures and hand movements. }\end{array}$ & 52 & 55.9 & 41 & 44.1 \\
\hline $\begin{array}{l}\text { Cognitive skills including the } \\
\text { therapists' intelligence and his } \\
\text { intuition. }\end{array}$ & 37 & 39.8 & 56 & 60.2 \\
\hline $\begin{array}{l}\text { Situational awareness including } \\
\text { incorporating the environment into } \\
\text { the exercises and selecting the right } \\
\text { environment for the therapy session. }\end{array}$ & 45 & 48.4 & 48 & 51.6 \\
\hline
\end{tabular}

Table 5. How much does skills helps in relieving pain?

\begin{tabular}{|c|c|c|c|c|c|}
\hline \multicolumn{2}{|c|}{ Little } & \multicolumn{2}{c|}{ Moderate } & \multicolumn{2}{c|}{ Large } \\
\hline Count & Percent $\%$ & Count & Percent $\%$ & Count & Percent $\%$ \\
\hline 15 & 20.8 & 21 & 29.2 & 36 & 50.0 \\
\hline
\end{tabular}

Table (5) illustrate (50\%) of subjects agree that communication skills involved in table 3 and 4 helped them in to relieving pain, (29.2\%) indicated it had moderate effect, and $(20.8 \%)$ showed it had little effect of communication skills on their pain.

\subsection{Inferential Statistic}

Our data showed statistically significant $(d f: 95, P: 0,00)$ in the effect of positive communication skills in reducing pain among orthopedic patient during physiotherapy session .No statistical significant ( $d f: 94, P: 0.216$ ) was observed between the gender and attitudes towards the impact of positive communication skills in the alleviation of pain of patient during the physiotherapy session. The results also showed no statistical significance between the; age, social status, occupation, level of education, economic status and attitudes towards the impact of positive communication skills in the alleviation of pain of patient during the physiotherapy session. Moreover, no statistical significant between Pain duration, number of sessions and how much communication skills help in relieving pain.

\section{Discussion}

The Results presented in the current study showed that $50 \%$ of the participant clearly revealed that positive communication skills used by the therapist through the session had high impact on alleviating pain intensity, (Table 5). There was no difference in respondents' attitudes towards the impact of positive communication skills in the alleviation of pain of patients during the physiotherapy session due to 
patient age, gender, occupation, social, economic status, and pain- related information. In addition there are no differences in respondents' attitudes towards the impact of positive communication skills in the alleviation of pain of patients during the physiotherapy session according to patient level of education. The educational background don't show differences, which agree all patients as a human had the same needs even though there is different cultural background, all of the patient have the same perception.

Physiotherapy plays a great role in the treatment of pain in different pathological conditions. Our results are in agreement with Butow P et al. [15] who studied the impact of communication on adherence in pain management and showed improved outcomes in primary care settings for patients with fibromyalgia and acute pain.

In addition, the result finding were in agreement with previous study which prepared by Lonsdale C [16] that showed the positive impact for communication skills training program for physiotherapist on chronic low back pain and patients adherence to home-based rehabilitation, we can conclude that communication skills play an essential role in physiotherapist sessions as method to relive patients pain.

The study participants manifest their respect and acceptance when physiotherapist explain treatment plan, that make them more self-aware about their condition and the level should be. Fong Ha et al. [17] showed that Patients reporting good communication with their doctor are more likely to be satisfied with their care, and especially to share pertinent information for accurate diagnosis of their problems, follow advice, and adhere to the prescribed treatment.

The communication skills used by the therapist through the session with patient had high positive effect to relieve pain similar to Rowbotham S et al. [18] represents a first step in demonstrating the potential impact of pain intensity on the communication of pain by revealing that people produce more speech and co-speech gestures when communicating about high versus low intensity pain, despite finding intense pain more difficult to communicate.

There was $55.9 \%$ of study sample gave positive impact regard communication skills related to Dynamic effective skills and facial gestures and hand movements. Such result was in agreement with DiMatteo M. R. et al. [19] that physicians who were successful at expressing emotion through their nonverbal communications tended to receive higher ratings from patients on the art of care than did physicians who were less effective communicators.

Most of the clients participated in this study replied that psychological status affect their health positively which approved by Dultamel K [10].

The impact of positive communication skills in the alleviation of pain of patients during the physiotherapy session is high , that may consistent with Khatri S. M. [20] that proposed the patient satisfaction may not depend on emotional quotient and job satisfaction of physiotherapist but probably depend on multiple factors like their knowledge, skills, experience and clinical expertise.

\section{Limitation of the Study}

- There is no studies has the same topic or similar studies hovering around the topic, so the literature review not fully identical of our topic, which make our study worth and essential.

- An experimental study with control group may be more precise and correlated to our topic.

- Only studies published in English were included.

\section{Conclusions and Recommendations}

Physiotherapist communication skills seems to play an essential role during sessions to help relive patients pain, achieve its aims and approved that positive communication skills has a great effect in reducing pain of orthopedic patient among physiotherapy session, also it facilitate reducing depression and increased motivation of the patient. Moreover, the results manifest that patients psychology and family members attitudes contribute to decreasing the intensity of pain when put a patient's concerns as a crucial point in the treatment plan. A reasonable approach would be to focus on specific communication skills, rather than on a general or 'full suite' of communication competences. It is necessary to develop methods of evaluation of communication competences, which diagnose educational needs of occupationally-active physiotherapists, and may be useful in constructing group and individual continuation of educational programs. An optimum approach would be diagnosis of the scope and level of lack of communication competence, and on this basis, the development of adequate training courses which focus on specific communication skills. Here are some of the recommendations to add important points in physiotherapy field.

- Further studies needed in this domain regard pain management special y in chronic pain management.

- Therapist must separate between his job satisfaction and dealing with patients.

- Integrate counseling services with physiotherapy department or clinic to be more honest and professional.

- There must be an intensive specialization course must conducted through physical therapy studying plan to teach students on how to integrate effective communication skills as critical point in treatment plan.

- The physiotherapist shall shed the light at the beginning on patient psyche and attitude to make comprehensive picture that will facilitate reaching to his goals

- There must take in consideration all point we discussed in our research especially first impressions

- The physiotherapist role to choose appropriate skill to specific methodology was used, because each method needs special communication skill more than another method.

There are many strategies the physiotherapists could use to strengthen their communication abilities, the following 
are a great start,

- Improving verbal communication skills is about enhancing the ability to use effective strategies to repair or avoid possible breakdown in communication; encouraging the use of patient-friendly language and familiarizing the physiotherapist with language (euphemisms, and colloquialisms) commonly used by patients

- Developing non-verbal skills therefore means increasing an awareness of body language, enabling physiotherapist to better read and interpret their patients' physical and emotional signs (expressions of anger, melancholy, etc.), while simultaneously mirroring their own verbal communication.

- Take in consideration that the first impression important for most of patients.

- Enhance trust with the patient from the outset.

- Use the appropriate activities and words to empower the patient and alleviation of anxiety and depression.

- Be genuine rather than manipulative.

- Empathize rather than remain detached.

- Use affirming responses.

- Employing active listening, voice management and cultural awareness.

\section{Acknowledgements}

We are indebted to our contributors, including those who provided advice and feedback on each of the many drafts. And we are grateful to our co-workers, colleagues, mentors, and respondents who participated in the study and shared their information with us.

\section{REFERENCES}

[1] WCPT .Declarations of Principle - Ethical Principles World Confederation forPhysiotherapists,http://www.wcpt.org/sites/wcpt.org/files/ files/Ethical_principles_Sept2011.pdf.

[2] Barringer B., Gold C.A. Therapeutic relationship and effective communication in C.A. Gold (Ed), Contemporary psychiatric-mental health nursing: The brain-behavior connection; 1998:61-47.

[3] Adler R., Rodman G. Understanding human communication. 5th ed. Orlando, FL: Holt, Rinehart and Windton. 1994.

[4] Henkin AB, Dee JR, Beatus J. Social communication skills of physical therapist students: An initial characterization. Journal of Physical Therapy Education. 2000; 14(2):38-32.

[5] Delany CM, Edwards I, Jensen GM, Skinner E Closing the gap between ethics. (Knowledge and practice through active engagement: an applied model of physical therapy ethics, 2010 .

[6] Thomson, D. Strategic, geographic targeting of housing and community development resources: A conceptual framework and critical review. Urban Affairs Review: 2008; 43, (5): 629-662.

[7] Lonsdale C, Hall AM, Williams GC, Mcdonough SM , Ntoumanis N, Murray, A, Hurley DA. Communication style and exercise compliance in physiotherapy (CONNECT): a cluster randomized controlled trial to test a theory-based intervention to increase chronic low back pain patients' adherence to physiotherapists' recommendations: study rationale, design, and methods, 2012.

[8] Newton BJ, Southall JL, Raphael JH, Ashford RL, LeMarchand K. A narrative review of the impact of disbelief in chronic pain. $2013 \mathrm{Sep}$; 14(3):161-71.

[9] Merskey N, Bogduk H. Classification of Chronic Pain Descriptions of Chronic Pain Syndromes and Definitions of Pain Terms. 2nd ed; 1994.

[10] Flor H, Hermann C. Biopsychosocial models of pain. In: Psychosocial Aspects of Pain: a Handbook for Health Care Providers. Progress in Pain Research and Management, edn. DworkinRH and Breitbart WS (eds). Seattle, IASP Press; 2004.

[11] Upshur CC, Gonzalo B, Luckmann R. They don't want anything to do with you: patient views of primary care management of chronic pain. Pain Medicine. 2010; 11:1798-1791.

[12] Magni G. On the relationship between chronic pain and depression when there is no organic lesion pain (in press). 1987; 31:1-21.

[13] DuHamel k. Increasing Pain Related Communication Skills to Improve Pain Management In Metastatic Breast Cancer Patients; 2002.

[14] James P. Rathmell, Jane C. Ballanyne, Scott M .Fishman. Bonica's Management of Pain. 2010: $4^{\text {th }}$ edi; 375-392.

[15] Butow P, Sharpe L. The impact of communication on adherence in pain management; 2013 Aug 6.

[16] Lonsdale C, Hall AM, Williams GC, Mcdonough SM, Ntoumanis N, Murray A, Hurley DA. Communication style and exercise compliance in physiotherapy (CONNECT): a cluster randomized controlled trial to test a theory-based intervention to increase chronic low back pain patients' adherence to physiotherapists' recommendations: study rationale, design, and methods; 2012.

[17] Fong Ha, J., Longnecker, N. Doctor-Patient Communication: A Review. The Ochsner Journal. 2010; 10(1):43-38.

[18] Rowbotham S, April J, Donna M, Wearden A, Holler J. Increased Pain Intensity Is Associated with Greater Verbal Communication Difficulty and Increased Production of Speech and Co-Speech Gestures; 2014.

[19] DiMatteo, M. R., Taranta, A., Friedman. H. S., \& Prince, 1. M. Predicting patient satisfaction physicians' nonverbal communication skills .Medical Care. 1980; 18:387-376.

[20] Khatri SM. Physiotherapist's emotional quotient and patients' satisfaction, Indian Journal of Physiotherapy \& Occupational Therapy. 2012; 6(1):149 p. 